\title{
EVALUATION OF THE EFFICACY OF INTRA-ARTICULAR INJ. MAGNESIUM SULPHATE IN COMBINATION WITH INJ. BUPIVACAINE FOR POST-OPERATIVE PAIN RELIEF FOLLOWING DIAGNOSTIC ARTHROSCOPY OF THE KNEE JOINT- A COMPARATIVE PROSPECTIVE STUDY
}

\author{
Champa Banavara Venkateshamurthy1, Ravindra Channagere Gangappa², Gurudutta Karnalli Nagarajarao ${ }^{3}$
}

${ }^{1}$ Assistant Professor, Department of Anaesthesiology and Pain Management, Shivamogga Institute of Medical Sciences, Shivamogga, Karnataka, India.

${ }^{2}$ Associate Professor, Department of Anaesthesiology and Pain Management, Shivamogga Institute of Medical Sciences, Shivamogga, Karnataka, India.

3Professor, Department of Anaesthesiology and Pain Management, Shivamogga Institute of Medical Sciences, Shivamogga, Karnataka, India.

\begin{tabular}{l}
\hline ABSTRACT \\
\hline BACKGROUND \\
Ambulatory arthroscopic knee surgery is now an established technique for the diagnosis and operative management of \\
intraarticular lesions. However, it is sometimes associated with moderate-to-severe post-operative pain. \\
The present study was undertaken to evaluate the efficacy of intraarticular Inj. Magnesium Sulphate as an adjuvant to Inj. \\
Bupivacaine for post-operative pain relief following diagnostic arthroscopy of the knee joint.
\end{tabular}

\section{MATERIALS AND METHODS}

This randomised controlled trial study of 60 eligible, consenting, ASA I and II physical status patients of either sex, undergoing elective diagnostic knee arthroscopy were enrolled in the study. All the cases were conducted under general anaesthesia. The patients were randomly allocated under two groups. Group A was the Control Group who received intraarticular $20 \mathrm{~mL}$ Inj. Bupivacaine $0.5 \%$ in addition to $10 \mathrm{~mL} 0.9 \%$ normal saline, ten minutes before the release of tourniquet at the completion of the procedure. Group B was the Study Group who received intraarticular $20 \mathrm{~mL}$ Inj. Bupivacaine $0.5 \%$ in addition to $10 \mathrm{~mL}$ Inj. Magnesium Sulphate 10\%, ten minutes before the release of tourniquet at the completion of the procedure. All the patients were successfully reversed, extubated and observed for post-operative pain relief assessed by VAS score $>4$ until the requirement of rescue analgesic drug in the form of IV Inj. Tramadol Hydrochloride $1 \mathrm{mg} / \mathrm{kg}$.

\section{RESULTS}

All 30 patients in Group B, i.e. case group who received Inj. Magnesium Sulphate along with Inj. Bupivacaine showed a three-fold increase in the analgesic duration post-operatively in comparison with the Control Group A, who received only Inj. Bupivacaine along with normal saline. The patients were highly satisfied with the quality of pain free period and no major complications were observed in either group.

\section{CONCLUSION}

The present study confirmed the fact that intraarticular administration of Magnesium Sulphate is highly effective as an adjuvant to Bupivacaine. This combination resulted in potentiating the analgesic duration of action post-operatively in patients undergoing diagnostic arthroscopy of the knee joint, which enabled them to undertake a fast-tracking course.

\section{KEY WORDS}

Knee Arthroscopy, Ambulatory, Post-Operative Pain, Bupivacaine, Magnesium Sulphate.

HOW TO CITE THIS ARTICLE: Venkateshamurthy CB, Gangappa RC, Nagarajarao GK. Evaluation of the efficacy of intra-articular inj. magnesium sulphate in combination with inj. bupivacaine for post-operative pain relief following diagnostic arthroscopy of the knee joint- a comparative prospective study. J. Evolution Med. Dent. Sci. 2018;7(39):4262-4267, DOI: 10.14260/jemds/2018/951

\section{BACKGROUND}

The current armamentarium of analgesic drugs and techniques for the management of post-operative pain continues to grow at a rapid rate. The expanding patient population requires a perioperative analgesic regimen that is

'Financial or Other Competing Interest': None.

Submission 17-08-2018, Peer Review 10-09-2018,

Acceptance 16-09-2018, Published 24-09-2018.

Corresponding Author:

Ravindra Channagere Gangappa

Associate Professor,

Department of Anaesthesiology and Pain Management,

McGann Teaching Hospital,

Shivamogga Institute of Medical Sciences,

Shivamogga, Karnataka, India.

E-mail: ravindracgdr@gmail.com

DOI: $10.14260 /$ jemds $/ 2018 / 951$ highly effective, has minimal side effects, is intrinsically safe and can be easily managed away from the hospital or surgical centre. This aspect is highly appropriated after knee arthroscopy. Recently, the advent of intricate conglomeration of best optical technology, tool technology and electronics has made rapid strides in minimally access approach, which represents the most important milestone in endoscopic approach to the joints. Thus, the knee arthroscopy has in many cases replaced the classic arthrotomy that was performed in the past. In the absence of a long surgical incision, the recovery after a knee arthroscopy is significantly faster and post-operative physiotherapy can be started immediately as compared to arthrotomy. However, the arthroscopic procedures may cause enough pain and swelling to delay the rehabilitation and return to work for up to two weeks after surgery. Therefore, aggressive pain management 
during the early post-operative period is essential and can enhance the convalescence after arthroscopic procedure.

Origin of the post-arthroscopic pain is a complex one and is not fully understood. Thus, various factors have been implicated in pain after arthroscopy and the effectiveness of intraarticular analgesia. According to Henderson RC et al (1990), ${ }^{1}$ Joshi GP et al (1992) ${ }^{2}$ and Whitford A et al (1997), ${ }^{3}$ the factors that would contribute to the post-operative pain following the arthroscopy include pre-operative pain score, type of surgery, seniority of surgeons, use of general or regional anaesthesia, volume of the drug injected, addition of adrenaline and timing of intraarticular injection in relation to tourniquet deflation etc.

Traditionally, administration of spinal anaesthesia has been the choice for these patients with variable postoperative analgesic duration. However, these days of fast tracking, arthroscopies are being carried out as day care surgeries and demands appropriate modification in anaesthesia approach. Thus, General Anaesthesia with numerous modern day intraarticular analgesics for postoperative pain management is order of the day. Various drugs that are commonly administered intraarticularly to provide post-operative analgesia after arthroscopic knee surgery are opioids, corticosteroids, local anaesthetics, clonidine, ketamine, etc., most recently the use of intraarticular magnesium sulphate has been studied extensively.

Intraarticular local anaesthetics are frequently used in perioperative pain management. Bupivacaine, an amide local anaesthetic, is often utilised because of its extended duration of action. ${ }^{4}$ Intraarticular bupivacaine in doses of 0.5 percent or less does not appear to be harmful to articular cartilage. 5

The recent discovery that opiate receptors exist in peripheral tissue including the intraarticular tissue is of great potential value while approaching the modalities of preventing or reducing post-operative pain. Their presence have been well documented and confirmed as specific receptor sites in the knee. ${ }^{6}$ Plasma profiles for morphine and its metabolites following intraarticular injection have been shown to be too low to produce effective systemic analgesia. ${ }^{2}$ Similarly, other opioids like fentanyl and meperidine have also been used intraarticularly with comparable analgesic effects. Use of intraarticular corticosteroids like triamcinolone and methylprednisolone has been studied extensively. They have a significant opioid sparing effect. But the onset of action of analgesic effect is considerably delayed but long-lasting.7 Similarly, intraarticular clonidine following arthroscopic knee surgery ${ }^{8-10}$ has been shown to prolong the duration of action of local anaesthetics ${ }^{11}$ as well as to selectively block the conduction of $\mathrm{A} d$ and $\mathrm{C}$ fibres. ${ }^{12}$ In addition to its local anaesthetic effects, clonidine may produce analgesia by releasing encephalin-like substances resulting in peripheral analgesia. ${ }^{13}$

$\mathrm{N}$-methyl-D-aspartate (NMDA) receptors play a major role in central nociceptive transmission, modulation and sensitisation of acute pain states. ${ }^{14}$ In addition to their central location, recent studies identified NMDA receptors peripherally in the skin, 15 muscles ${ }^{16}$ and knee joints ${ }^{17}$ and found that they play a role in sensory transmission of noxious signals. In its inactive state, the NMDA receptor is blocked by the presence of a centrally positioned magnesium ion. Afferent activity in nociceptor fibres dislodges the central magnesium ion from the NMDA receptor, therefore allowing calcium influx into the cell.
Magnesium can be considered as a physiological blocker of NMDA receptors. ${ }^{18}$ Magnesium therapy has been shown to be potentially beneficial in eclampsia, ${ }^{19}$ headache ${ }^{20}$ and acute migraine attacks. ${ }^{21}$ More recently, it has been demonstrated to reduce post-operative analgesic requirements. 22,23 Thus, magnesium appears to have cornered the attention of several research workers who are concentrating on its effects on post-operative pain relief following knee arthroscopic procedures. The primary aim of this clinical study was to evaluate the efficacy of intraarticular Inj. Magnesium sulphate as an adjuvant to Inj. Bupivacaine for post-operative pain relief following diagnostic arthroscopy of the knee joint.

\section{MATERIALS AND METHODS}

A randomised controlled trial study "Evaluation of the efficacy of intraarticular Inj. Magnesium sulphate in combination with Inj. Bupivacaine for post-operative pain relief following diagnostic arthroscopy of the knee joint" was conducted on 60 eligible ASA 1 and 2 patients, who underwent elective diagnostic arthroscopy of the knee joint under general anaesthesia at the Shivamogga Institute of Medical Sciences, Shivamogga, from June 2016 to June 2018. ASA grade other than I and II. The study was double blinded. Procedures requiring surgical interventions, need for postoperative intraarticular drainage and contraindication for intraarticular deposition of Inj. Magnesium Sulphate and knee surgeries under regional anaesthetic techniques were excluded from the study.

Pre-operatively, patients underwent a detailed history taking and physical examination before recruiting them under the study. Patients were taken into confidence after explaining regarding the mode of anaesthesia, the postoperative pain relief that will be instituted and the patient's participation in evaluating the duration of post-operative analgesia under the study. For this purpose, all the patients were counselled in their native language regarding their role in the study with respect to the post-operative pain assessment and were familiarised with the Visual Analogue Scale used in the study. Further, the demonstration of preoperative pain assessment was done using the visual analogue scale with score 0 to $10 \mathrm{~cm}(0-100 \mathrm{~mm}, 0-$ No Pain, 10 - Worst Possible Pain) and the VAS score was recorded with the active participation of the patient. A written informed consent was taken from the patients after explaining the modalities of the study. The results of the following investigations were reviewed: Weight, Height and BMI, ECG; Chest X-ray; Blood Sugar, Serum Electrolytes, Complete haemogram including bleeding and clotting time, renal and liver function profile. Eligible patients were then considered and enrolled under the study. Patients were randomised into Control Group and Study Group based on computer generated randomisation-

\section{Group A: Control Group}

Received a combination of $10 \mathrm{~mL}$ of Inj. $0.9 \%$ Normal saline $+20 \mathrm{~mL}$ of $0.5 \%$ Inj. Bupivacaine hydrochloride $0.5 \%, 20 \mathrm{~mL}$ intraarticularly at the conclusion of arthroscopy.

\section{Group B: Study Group}

Received a combination of $10 \mathrm{~mL}$ of Inj. Magnesium sulphate $10 \%$ and $20 \mathrm{~mL}$ of $0.5 \%$ Inj. Bupivacaine hydrochloride intraarticularly at the conclusion of arthroscopy. 
No oral premedication was administered in the ward under the protocol. The arthroscopic procedure was conducted under general anaesthesia. During the surgery the patient monitoring included: Continuous Electrocardiogram, Heart rate, Pulse oximetry, Capnograph and NIBP at five minutes interval. The arthroscopy was conducted under conventional general anaesthesia. Inj. Pentazocine $0.4 \mathrm{mg} / \mathrm{kg}$ IV was the only analgesic administered during the surgery. Appropriate sized LMA or an endotracheal tube was used to control the airway. Tourniquet on the thigh was inflated to a pressure of $300 \mathrm{mmHg}$ before the start of arthroscopy. At the end of the surgical intervention, the study drug was prepared and deposited the drug intraarticularly into the operated knee under aseptic care by the surgical team, and the time of intraarticular deposition was noted. The tourniquet was deflated 10 minutes after the intraarticular drug deposition. The patients were reversed and extubated. They were further monitored at the PACU during the study period.

\section{Post-Operative Monitoring}

1. Vital Parameters: The heart rate, blood pressure and respiratory rate were measured and recorded at regular intervals.

2. Pain Assessment: It was done using the Visual Analogue Scale with score 0 to $10 \mathrm{~cm}(0-100 \mathrm{~mm}, 0=$ No Pain, $10=$ Worst Possible Pain) at regular intervals of $0.5,2,4,6,8$, $10,12,16,20$ and 24 hours post-operatively, i.e. till they required rescue analgesia at a VAS score of $>4$.

3. Rescue Analgesia: It was provided with Inj. Tramadol hydrochloride $1 \mathrm{mg} / \mathrm{kg}$ IV.

4. Analgesic Duration: It was calculated from the time of intraarticular deposition of the study drug to the first requirement of rescue analgesia as defined by the VAS of $>4$.

5. Tourniquet Site Pain: Patients were asked to comment on the tourniquet site pain (Yes/No).

6. Other Complications.

The patients were monitored to recognise and rule out any local anaesthetic and/or magnesium sulphate induced toxicity that is expected during the post-operative period. This included complications like nausea/ vomiting, respiratory depression, convulsions, hypotension, paraesthesia etc. These were treated appropriately.

Descriptive statistical analysis was carried out in the present study. Results on continuous measurements were presented on Mean \pm SD (Min-Max) and results on categorical measurements were presented in Number (\%). Significance was assessed at $5 \%$ level of significance, i.e. a p-value $<0.05$. Student's ' $t$ ' test (two-tailed, independent) was used to find the significance of study parameters on continuous scale between two groups (Intergroup analysis). 2 x 6 Fisher's Exact test was used to find the significance of study parameters on categorical scale between two groups. Homogeneity of samples based on age, gender and other study characteristics was done using the student's ' $t$ ' test and Chi-square test.

\section{Sample Size Calculation}

$\alpha=Z \alpha=1.960$

$\beta=\mathrm{Z} \beta=0.842$

$A=(1 / q 1+1 / q 0)=4.000$
$\mathrm{B}=(\mathrm{Z} \alpha+\mathrm{Z} \beta)^{2}=7.849$

Standardised effect size $=\mathrm{E} / \mathrm{s}=0.72$

Total Group Size $=\mathrm{N}=\mathrm{AB} /(\mathrm{E} / \mathrm{s})^{2}=60.56$

So $\mathrm{N}_{1}=30$ and $\mathrm{N}_{2}=30$

\section{RESULTS}

The demographic data with respect to Age, Gender distribution, Weight, Height and ASA status was comparable between the groups. The mean tourniquet time was 47.46 minutes in Group A and 47.36 minutes in Group B, attracted no statistical significance. The mean VAS scores at rest recorded post-operatively were significantly lower in Group $B$ than in Group A. The analgesic duration was significantly longer in Group B than in Group A, i.e. $18.17 \pm 3.15$ hrs. in Group B as against $6.40 \pm 1.59$ hrs. in Group A. The statistical analysis was highly significant with $p$-value $<0.001$. The significantly longer analgesic duration in Group B in comparison with Group A confirmed the fact that the Inj. Magnesium exerts a significant adjuvant action on the Inj. Bupivacaine by prolonging its duration of action by almost three times. A very large effect of Inj. MgSo4 with effect size of 4.68 was seen. Inj. Magnesium sulphate exerts significant extended analgesic effect when administered intraarticularly following diagnostic knee arthroscopies. The haemodynamics in the form of pulse, blood pressure and respiratory rate remained stable in the post-operative period in both the groups indicating the safety of use of Magnesium sulphate. There were no major complications observed in both the groups in the post-operative period. Minor late side effects like nausea/ vomiting could be attributed to the use of Inj. Tramadol hydrochloride as rescue analgesic. No systemic side effects following systemic absorption of the intraarticularly injected Magnesium sulphate was noted in Group B.

\section{DISCUSSION}

Intraarticular local anaesthetics following knee arthroscopy was studied by Nole $\mathrm{R}$ et $\mathrm{al}^{5}$ as early as 1985 . These authors preferred to deposit Inj. Bupivacaine, an amide local anaesthetic for its extended duration of action. According to Nole R et al (1985), 5 intraarticular Inj. Bupivacaine in doses of 0.5 percent or less does not appear to be harmful to articular cartilage. Adjuvants are compounds, which by themselves have undesirable side-effects or low potency but in combination with opioids allow a reduction of narcotic dosing for post-operative pain control. Adjuvants are needed for post-operative pain management due to side-effects of opioid analgesics which hinder recovery, especially in the increasingly utilised ambulatory surgical procedures. Adjuvants are also needed to prolong the duration of local anaesthetics.

Inj. Magnesium sulphate is easily available at low cost. Intraarticular use of Inj. Magnesium sulphate is an effective adjuvant to Bupivacaine for post-operative analgesia following diagnostic arthroscopy of the knee joint. The low concentration of Magnesium sulphate used intraarticularly has significant analgesic benefit. The analgesic benefit may be attributed to the NMDA antagonistic property of Magnesium. In concentrations of $10 \%, 10 \mathrm{~mL}$ Magnesium sulphate can safely be used intraarticularly without any major side effects on its systemic absorption. Use of intraarticular Inj. Magnesium sulphate along with Inj. Bupivacaine following knee arthroscopies allows for early ambulation and makes diagnostic knee arthroscopy the day care surgery a reality. 


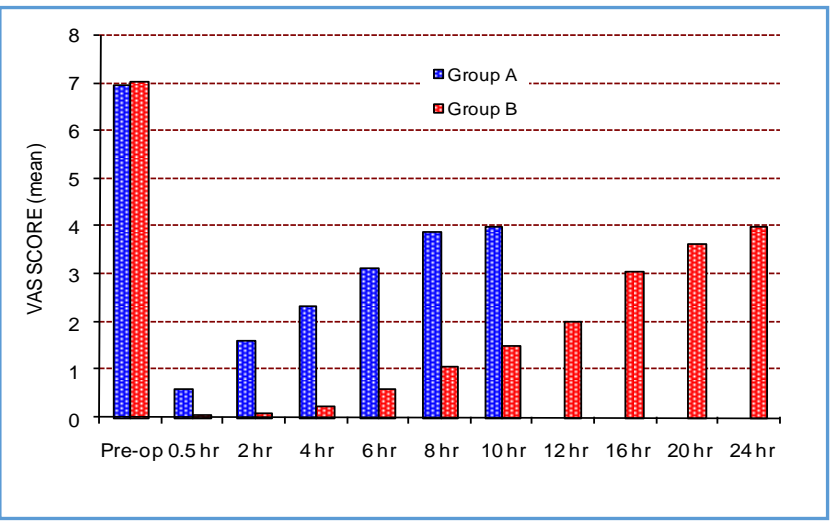

Comparison of VAS Score

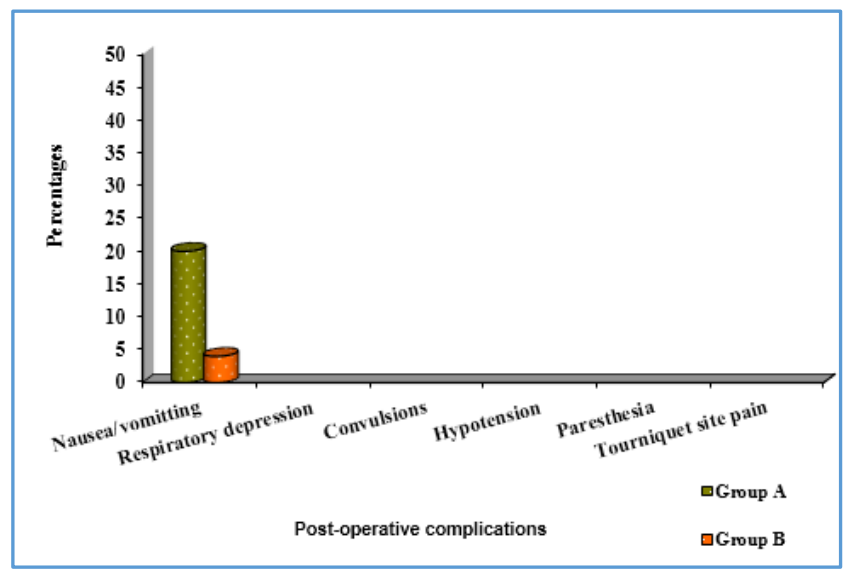

Comparison of Post-Operative Analgesia using VAS

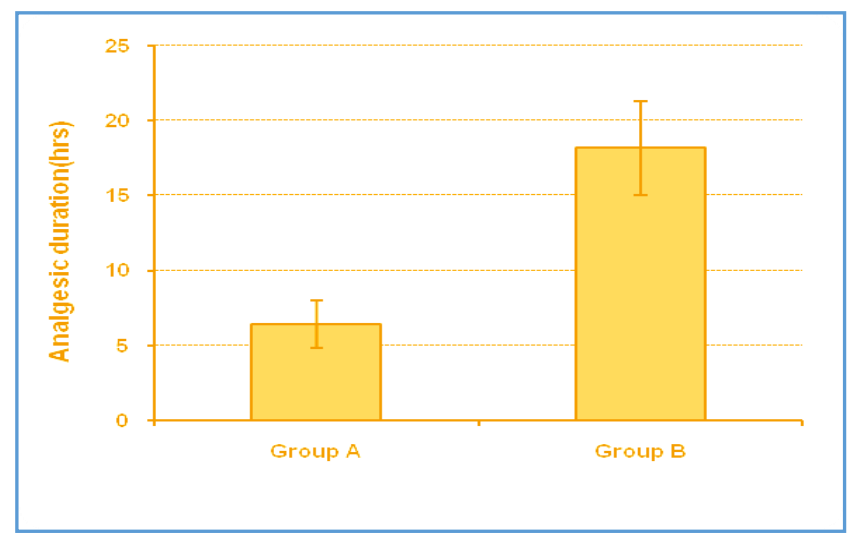

Comparison of Mean Analgesic Duration

Special focus of interest is on the role played by the NMDA antagonists in the attenuation of the post-operative pain since a long time. The prototype Inj. Ketamine has been extensively studied by Yatindra Kumar Batra et al (2005) ${ }^{24}$ for its adjuvant action to local anaesthetics after intraarticular injection. Fawcett WJ et al (1999)18 have shown that Magnesium can be considered as a physiological blocker of NMDA receptors. Koinig $\mathrm{H}$ et al (1998) ${ }^{18}$ and Levaux $\mathrm{Ch}$ et al (2003) 22 have demonstrated a reduction in post-operative analgesic requirements with the use of Inj. Magnesium sulphate intraoperatively. Previous studies investigating the analgesic efficacy of systemic administration of Inj. Magnesium sulphate have shown conflicting results. After hysterectomy, reduced analgesic requirements, reduced discomfort and better sleep quality have been reported by Tramèr et al (1996). ${ }^{25}$
Koinig $\mathrm{H}$ et al (1998) ${ }^{23}$ conducted a randomised, doubleblinded study on patients undergoing arthroscopic knee surgery with total IV anaesthesia. The patients received either Magnesium sulphate $50 \mathrm{mg} / \mathrm{kg}$ pre-operatively and 8 mg.kg-1.h-1 intraoperatively. They concluded that IV Magnesium sulphate administration reduces intra-operative and post-operative analgesic requirements. Their results demonstrate that systemic administration of Magnesium can be an adjuvant to perioperative analgesic management.

Levaux et al (2003) ${ }^{22}$ had studied the effect of intraoperative systemic administration of Magnesium sulphate on pain relief and patient comfort after major lumbar orthopaedic surgery and they concluded that systemic administration of Magnesium sulphate reduced postoperative opioid consumption and pain scores with improvement in first night's sleep and the global satisfaction scores.

Intrathecal administration of Magnesium has been studied by Buvanendran A et al (2002). ${ }^{26}$ The patients were randomised to receive either intrathecal Fentanyl $25 \mu \mathrm{g}$ plus saline or Fentanyl $25 \mu \mathrm{g}$ plus Magnesium sulphate $50 \mathrm{mg}$ as part of a combined spinal epidural technique. There was significant prolongation in the median duration of analgesia (75 mins) in the Magnesium plus Fentanyl group compared with the Fentanyl group (60 mins). They concluded that intrathecal Magnesium prolongs spinal opioid analgesia in humans and suggest that the availability of an intrathecal $\mathrm{N}$ methyl-D-aspartate antagonist could be of clinical importance for pain management.

The recently published data on intraarticular deposition of Inj. Magnesium sulphate use by Bondok RS et al (2006), ${ }^{27}$ Mohamed R Hemida et al (2006) ${ }^{28}$ and Elsharnouby et al $(2008)^{29}$ supports the use of Inj. Magnesium sulphate for its extended analgesic benefits without any adverse effects on the cartilages.

The mechanism of peripheral antinociceptive effect of NMDA antagonism has not been precisely defined. It has been hypothesised to occur through an analgesic and antiinflammatory effect. In the study conducted by Hong-Tao Liu et al (2001),30 they have shown that NMDA antagonists reduce the excitability of nociceptive input terminals of $\mathrm{C}$ fibres, which play a role in the central processing of pain. The anti-inflammatory action in the peripheral tissues occurs through antagonising the release of inflammatory mediators such as histamine, cytokines and serotonin which in turn excite nociceptors. 31

The analgesic effect of intraarticular Magnesium is evident. The present study as well as the previous studies has shown a significant benefit with the use of intraarticular magnesium. Inj. Magnesium sulphate in concentrations of $10 \%$ has been shown to be safe when used intraarticularly by NM Elsharnouby et al in an animal study on rat knee joints.

The results of the present study correlate well with the published data by the previous studies, where they have used intraarticular Magnesium along with Inj. Bupivacaine. Furthermore, no major side effects indicating the systemic side effects of Magnesium were noted during the present study. In the present study, where $10 \mathrm{~mL}$ of $10 \% \mathrm{Inj}$ Magnesium sulphate (total $1 \mathrm{gm}$ ) along with $20 \mathrm{~mL}$ of $0.5 \%$ Inj. Bupivacaine has been deposited intraarticularly in the Study Group (B) and the other Control Group (A) received 10 $\mathrm{mL}$ normal saline along with $20 \mathrm{~mL}$ of $0.5 \% \mathrm{Inj}$. Bupivacaine 
intraarticularly. The study demonstrated the advantages of Magnesium sulphate used intraarticularly as an adjuvant to Bupivacaine in enhancing the post-operative analgesic duration following knee arthroscopy. These advantages are obtained without any post-operative complications involving cardiovascular or respiratory systems following intraarticular deposition of Magnesium sulphate.

The present study has shown that low concentrations of intraarticular Magnesium are efficient for pain relief. Intraarticular Inj. Magnesium sulphate is an efficient adjuvant to Inj. Bupivacaine following knee arthroscopy. Also, that none of the patients who received intraarticular Magnesium had any significant side effects.

The present study has shown the benefits of the intraarticular use of Magnesium sulphate for post-operative pain relief following knee arthroscopy, conducted on 60 patients. The sample size is small to comment on the safety of the use of intraarticular Magnesium sulphate. Though no major complications were observed in the present study, a large study involving higher number of patients might evaluate the safety of the use of intraarticular Magnesium sulphate.

The limitations of the present study may be that the estimation of serum levels of Magnesium following its intraarticular administration has not been carried out. The available literature did not warrant such a study, which would alter the course of the study. The other one is the absence of a placebo group.

\section{CONCLUSION}

The present study confirmed the fact that intraarticular administration of magnesium sulphate is highly effective as an adjuvant to Bupivacaine. This combination resulted in potentiating the analgesic duration of action post-operatively in patients undergoing diagnostic arthroscopy of the knee joint, which enabled them to undertake a fast-tracking course.

\section{REFERENCES}

[1] Henderson RC, Campion ER, DeMasi RA, et al. Post arthroscopy analgesia with bupivacaine. A prospective, randomized, blinded evaluation. Am J Sports Med 1990;18(6):614-7.

[2] Joshi GP, McCarroll SM, Cooney CM, et al. Intraarticular morphine for pain relief after knee arthroscopy. J Bone Joint Surg Br 1992;74(5):749-51.

[3] Whitford A, Healy M, Joshi GP, et al. The effect of tourniquet release time on the analgesic efficacy of intraarticular morphine after arthroscopic knee surgery. Anesth Analg 1997;84(4):791-3.

[4] Moore DC, Bridenbaugh LD, Thompson GE, et al. Bupivacaine: a review of 11,080 cases. Anesthesia \& Analgesia 1978;57(1):42-53.

[5] Nole R, Munson NM, Fulkerson JP. Bupivacaine and saline effects on articular cartilage. Arthroscopy 1985;1(2):123-7.

[6] Lawrence AJ, Joshi GP, Michalkiewicz A, et al. Evidence for analgesia mediated by peripheral opioid receptors in inflamed synovial tissue. European J Clin Pharmacol 1992;43(4):351-5.

[7] Wang JJ, Ho ST, Lee SC, et al. Intraarticular triamcinolone acetonide for pain control after arthroscopic knee surgery. Anesthesia \& Analgesia 1998;87(5):1113-6.

[8] Gentili M, Juhel A, Bonnet F. Peripheral analgesic effect of intraarticular clonidine. Pain 1996;64(3):593-6.

[9] Joshi W, Reuben SS, Kilaru PR, et al. Postoperative analgesia for outpatient arthroscopic knee surgery with intraarticular clonidine and/or morphine. Anesthesia \& Analgesia 2000;90(5):1102-6.

[10] Reuben SS, Connelly NR. Postoperative analgesia for outpatient arthroscopic knee surgery with intra articular clonidine. Anesthesia \& Analgesia 1999;88(4):729-33.

[11] Gaumann DM, Brunet PC, Jirounek P. Clonidine enhances the effects of lidocaine on C-fiber action potential. Anesthesia \& Analgesia 1992;74(5):719-25.

[12] Butterworth JF 5th, Strichartz GR. The alpha 2adrenergic agonists clonidine and guanfacine produce tonic and phasic block of conduction in rat sciatic nerve fibers. Anesthesia \& Analgesia 1993;76(2):295301.

[13] Nakamura M, Ferreira SH. Peripheral analgesic action of clonidine: mediation by release of endogenous enkephalin-like substances. European J Pharmacol 1988;146(2-3):223-8.

[14] Woolf CJ. Somatic pain-pathogenesis and prevention. British Journal of Anaesthesia 1995;75(2):169-76.

[15] Iwatsu 0, Ushida $T$, Tani $T$, et al. Peripheral administration of magnesium Sulfate and ketamine hydrochloride produces hypethesia to mechanical stimuli in humans. J Health Sci 2002;48(1):69-72.

[16] Cairns BE, Svensson P, Wang K, et al. Activation of peripheral NMDA receptors contributes to human pain and rat afferent discharges evoked by injection of glutamate into the masseter muscle. J Neurophysiol 2003;90(4):2098-105.

[17] Lawand NB, Willis WD, Westlund KN. Excitatory amino acid receptor involvement in peripheral nociceptive transmission in rats. Eur J Pharmacol 1997;324(2-3):169-77.

[18] Fawcett WJ, Haxby EJ, Male DA. Magnesium: physiology and pharmacology. British Journal of Anaesthesia 1999;83(2):302-20.

[19] Eclampsia Trial Collaborative Group. Which anticonvulsant for women with eclampsia? Evidence from the Collaborative Eclampsia Trial. Lancet 1995;345(8963):1455-63.

[20] Ginder S, Oatman B, Pollack M. A prospective study of i.v. magnesium and i.v. prochlorperazine in the treatment of headaches. J Emerg Med 2000;18(3):3115.

[21] Demirkaya S, Vural 0, Dora B, et al. Efficacy of intravenous magnesium sulphate in the treatment of acute migraine attacks. Headache 2001;41(2):171-7.

[22] Levaux Ch, Bonhomme V, Dewandre PY, et al. Effect of intra-operative magnesium sulphate on pain relief and patient comfort after major lumbar orthopaedic surgery. Anaesthesia 2003;58(2):131-5.

[23] Koinig H, Wallner T, Marhofer P, et al. Magnesium sulfate reduces intra- and postoperative analgesic requirements. Anesthesia \& Analgesia 1998;87(1):206-10. 
[24] Batra YK, Mahajan R, Bangalia SK, et al. Bupivacaine/ketamine is superior to intraarticular ketamine analgesia following arthroscopic knee surgery. Canadian Journal of Anesthesia 2005;52(8):832-6.

[25] Tramèr MR, Schneider J, Marti RA, et al. Role of magnesium sulfate in postoperative analgesia. Anesthesiology 1996;84(2):340-7.

[26] Buvanendran A, McCarthy RJ, Kroin JS, et al. Intrathecal magnesium prolongs fentanyl analgesia: a prospective, randomized, controlled trial. Anesthesia \& Analgesia 2002;95(3):661-6.

[27] Bondok RS, Abd El-Hady AM. Intraarticular magnesium is effective for postoperative analgesia in arthroscopic knee surgery. British Journal of Anaesthesia 2006;97(3):389-92.
[28] Hemida MR. Intraarticular magnesium sulphate versus bupivacaine for postoperative analgesia in outpatient arthroscopic knee surgery. Tanta Med Sci Journal 2006;1(4):32-40.

[29] Elsharnouby NM, Eid HE, Abou Elezz NF, et al. Intraarticular injection of magnesium sulphate and/or bupivacaine for postoperative analgesia after arthroscopic knee surgery. Anesthesia \& Analgesia 2008;106(5):1548-52.

[30] Liu HT, Hollmann MW, Liu WH, et al. Modulation of NMDA receptor function by ketamine and magnesium: Part I. Anesth Analg 2001;92(5):1173-81.

[31] Lawland NB, Reddig WJ, Cashin AE, et al. NMDA receptors and associated signaling pathways: a role in knee joint blood flow regulation. Eur J Pharmacol 2004;499(1-2):155-61. 